\title{
Gearing up for survival - HSP-containing granules accumulate in quiescent cells and promote survival
}

\author{
Ruofan Yu and Weiwei Dang* \\ Huffington Center on Aging, Department of Molecular and Human Genetics, Baylor College of Medicine, Houston, TX 77030, USA. \\ * Corresponding Authors: \\ Weiwei Dang; 1 Baylor Plaza, N803.6, Mailstop BCM230, Houston, TX 77030, USA; Phone: +1 (713) 798-1565; E-mail: \\ Weiwei.Dang@bcm.edu
}

The budding yeast Saccharomyces cerevisiae proliferates in a logarithmic fashion when growing in glucose-containing rich media. When all carbon sources in the environment are depleted, the yeast cells enter the stationary phase. There are two types of stationary cells: the quiescent (Q) cells, which temporarily cease dividing before nutrition replenishes, and the non- quiescent (NQ) cells that keep proliferating [1]. Both physical and biochemical differences exist between the $Q$ and $N Q$ cell types. For example, $Q$ cells have a higher density and the mRNA and protein profiles in the two cell types are also profoundly different $[2,3]$. Apart from these features, $Q$ cells have been reported to have higher resistance to stress and a longer chronological lifespan.

Cells within the stationary phase are commonly observed to have granule structures, containing stress response-related factors [4] and may thus play a role in the elevated survival ability of $Q$ cells. In this issue, Lee et al. reports that distinct granules are formed in $Q$ and NQ cells, which determines their respective cell fates [5]. The authors asked whether different kinds of granules were distributed uniformly between $Q$ and $N Q$ cells, and found that most granule structures are enriched in NQ cells with the exception of Hsp42-associated stationary phase granules (Hsp42-SPGs) (Fig. 1). Using a mutated form of luciferase that misfolds upon heat shock, they further demonstrated that Hsp42-SPGs contributes to stress response of $Q$ cells by facilitating clearance of protein aggregates, which is consistent with the reported function of Hsp42 to prevent unspecific protein aggregation [6]. Lee et al. also proved that the $Q$ cells reenter the mitotic cycle more quickly after nutrition replenishment [5], which further establishes the phenotypical difference between the two cell types (Fig. 1). Since $Q$ and NQ cells come from the same clone, their formation has been proposed to be a process of cell differentiation [3]. Consistent with this idea, this paper shows that NQ cells are indeed committed to their cell fate: most NQ cells remain non-quiescent even after re-entering the cell cycle (Fig. 1). This study, coupled with other research on yeast quiescence, will likely provide valuable insight into cell differentiation in higher eukaryotes.

A key question remains to be addressed in the field: what determines a cell to become quiescent or non-

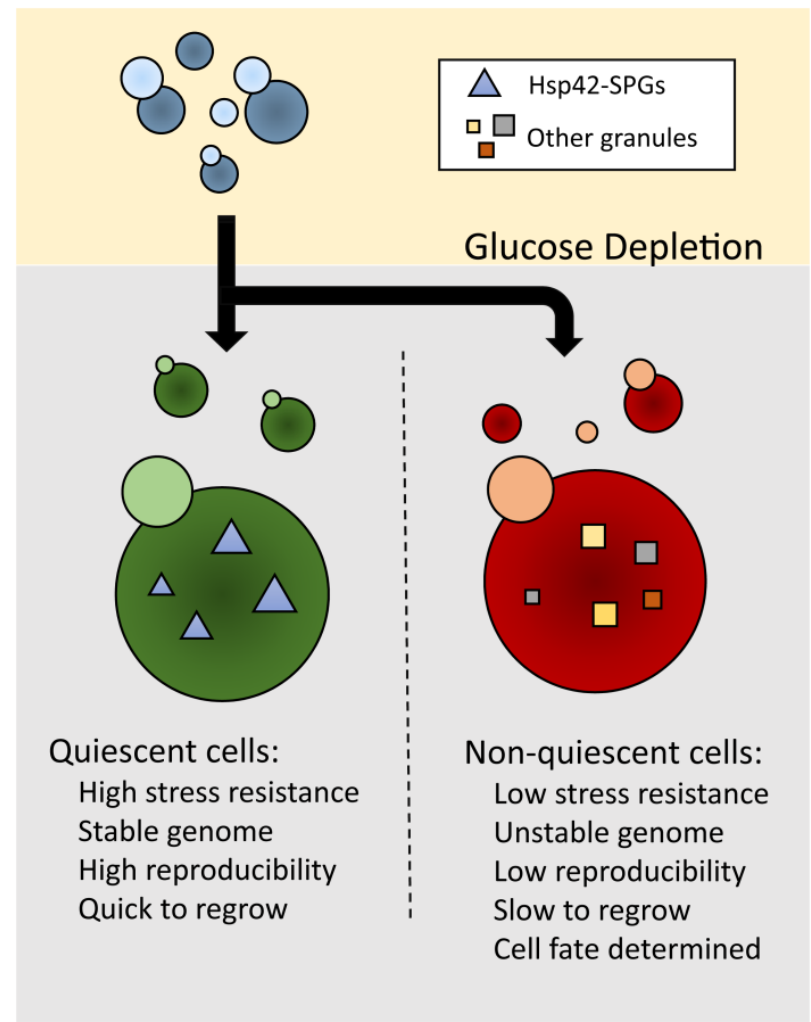

FIGURE 1: Hsp42-associated stationary phase granules (Hsp42SPGs) confer features for quiescent cells (Q) that are distinct from non-quiescent cells (NQ). 
quiescent ? The molecular pathways that regulate this cellfate commitment remain elusive. Davidson et al. [7] suggested that differentiation depends on epigenetic changes rather than DNA mutation. This is probable since acetylCoA metabolism changes upon entering the stationary phase [8], and acetyl- CoA, being the major acetyl group donor, has a substantial impact on protein acetylation. While some explanation is still required for the drastic difference between the two cell types, the molecular mechanisms linking environmental changes with quiescence will be an important step in the long-lasting study of the relationship between environment and aging.

\section{ACKNOWLEDGMENTS}

This work is supported by NIH grant AG037646 and CPRIT scholar award (R1306) to WD. RY is supported by the Cullen Scholarship in Molecular Genetics from the Cullen Foundation.

\section{REFERENCES}

1. Gray JV, Petsko GA, Johnston GC, Ringe D, Singer RA, and WernerWashburne M (2004). "Sleeping beauty": quiescence in Saccharomyces cerevisiae. Microbiol Mol Biol Rev 68(2): 187-206.

2. Aragon AD, Rodriguez AL, Meirelles O, Roy S, Davidson GS, Tapia PH, Allen C, Joe R, Benn D, and Werner-Washburne M (2008). Characterization of differentiated quiescent and nonquiescent cells in yeast stationary-phase cultures. Mol Biol Cell 19(3): 1271-1280.

3. Palková Z, Wilkinson D, and Váchová L (2014). Aging and differentiation in yeast populations: elders with different properties and functions. FEMS Yeast Res 14(1): 96-108.

4. Shah KH, Zhang B, Ramachandran V, and Herman PK (2013). Processing body and stress granule assembly occur by independent and differentially regulated pathways in Saccharomyces cerevisiae. Genetics 193(1): 109-123.

\section{CONFLICT OF INTEREST}

The authors declare no conflict of interest.

\section{COPYRIGHT}

(C) $2016 \mathrm{Yu}$ and Dang. This is an open-access article released under the terms of the Creative Commons Attribution (CC BY) license, which allows the unrestricted use, distribution, and reproduction in any medium, provided the original author and source are acknowledged.

Please cite this article as: Ruofan Yu and Weiwei Dang (2016). Gearing up for survival - HSP-containing granules accumulate in quiescent cells and promote survival. Microbial Cell 3(3): 95-96. doi: $10.15698 / \mathrm{mic} 2016.03 .481$

5. Hsin-Yi Lee, Kuo-Yu Cheng, Jung-Chi Chao and Jun-Yi Leu (2016). Differentiated cytoplasmic granule formation in quiescent and nonquiescent cells upon chronological aging. Microbial Cell 3(3):109-119.

6. Haslbeck M, Franzmann T, Weinfurtner D, and Buchner J (2005). Some like it hot: the structure and function of small heat-shock proteins. Nat Struct Mol Biol 12(10): 842-846.

7. Davidson GS, Joe RM, Roy S, Meirelles O, Allen CP, Wilson MR, Tapia PH, Manzanilla EE, Dodson AE, Chakraborty S, Carter M, Young S, Edwards B, Sklar L, and Werner-Washburne M (2011). The proteomics of quiescent and nonquiescent cell differentiation in yeast stationaryphase cultures. Mol Biol Cell 22(7): 988-998.

8. Dos Santos MM, Gombert AK, Christensen B, Olsson L, and Nielsen J (2003). Identification of in vivo enzyme activities in the cometabolism of glucose and acetate by Saccharomyces cerevisiae by using $13 \mathrm{C}$ labeled substrates. Eukaryotic Cell 2(3): 599-608. 